\title{
Penetration of timolol eye drops into human aqueous humour: the first hour
}

\author{
CALBERT I PHILLIPS, ' R SHAYLE BARTHOLOMEW,' ANTHONY M LEVY,' \\ JEFFREY GROVE, ${ }^{2}$ AND ROGER VOGEL ${ }^{3}$
}

From the 'Department of Ophthalmology, University of Edinburgh and Princess Alexandra Eye Pavilion, Royal Infirmary, Edinburgh; ${ }^{2}$ Merck Sharp and Dohme-Chibret Research Centre, Riom, France; and ${ }^{3}$ Merck Sharp and Dohme Ltd, Hertford Road, Hoddesdon, Hertfordshire

SUMMARY Samples of aqueous humour were removed from 26 eyes at the start of cataract extraction. Two drops of timolol $0 \cdot 5 \%$ had been instilled into the conjunctival sac $12-71$ minutes before operation. Analysis by gas chromatography showed a mean timolol concentration of 55.46 $\mathrm{ng} / \mathrm{mg}$, with a range of 8 to $100 \mathrm{ng} / \mathrm{mg}$.

In a previous paper' we reported concentrations of timolol in human aqueous humour after the first hour following instillation into the conjunctival sac of 2 drops of timolol eye drops $0.5 \%(500 \mu \mathrm{g}$ per $100 \mathrm{mg})$ : these ranged from $150 \mathrm{ng}$ per $100 \mathrm{mg}$ between the first and second hours to $10 \mathrm{ng}$ per $100 \mathrm{mg}$ towards the end of 7 hours, that is, there seemed to be a progressive fall from the time of initial observations. Aqueous samples were taken in the preliminary stages of cataract extraction. These data provided no information about concentrations during the first hour following instillation of the eye drops, an omission made good in the present series.

Previous studies have been done in albino rabbits either by measuring total radioactivity after instillation of labelled drugs ${ }^{2-5}$ or by assaying $\beta$ blockers by gas chromatography. ${ }^{2-6}$ Aqueous levels after instillation of timolol were higher than those achieved after atenolol or metoprolol, ${ }^{4}$ whereas propranolol, practolol, oxprenolol, and alprenolol gave higher aqueous humour levels than timolol. ${ }^{6}$

\section{Patients and methods}

Two drops of timolol $0 \cdot 5 \%$ were instilled into the conjunctival sacs of 30 patients $12-71$ minutes before removal of samples of aqueous humour at cataract extraction. In three cases the volume was too small to allow analyses, while in one case the time interval was not clearly enough recorded; accordingly these were discarded, to leave 26 valid observations.

At the beginning of the operation of cataract Correspondence to: Professor C I Phillips, Eye Pavilion, Chalmers Street, Edinburgh EH3 9HA. extraction a conjunctival flap was made, then a limbal groove. In some patients a tuberculin needle was used to perforate the deepest layers of the corneoscleral junction to aspirate aqueous, while in others the incision was deepened into the anterior chamber for 1-2 mm at 12 o'clock to allow entry of the blunt tip of a Rycroft cannula. Each sample was stored in a small stoppered plastic tube at $-80^{\circ} \mathrm{C}$ or in dry ice during transport.

Most patients had general anaesthesia (halothane) preceded by diazepam (Valium) $10 \mathrm{mg}$. Some had local, including retrobulbar, anaesthesia. All had phenylephrine $10 \%$ eye drops preoperatively, and some had atropine $1 \%$ eye drops 24 hours and 1-2 hours before operation.

\section{CHEMICAL ANALYSIS}

A modification of the procedure of Tocco et al. ${ }^{7}$ was employed for the assay of timolol. The method is based on the gas chromatographic electron-capture determination of the heptafluorobutyric ester derivative of timolol with desmethyltimolol as internal standard. The chromatograph used was a model 5730 (Hewlett-Packard) equipped with a ${ }^{63} \mathrm{Ni}$ electron capture detector. A $1 \cdot 1 \mathrm{~m} \times 3 \mathrm{~mm}$ glass column packed with $3 \%$ OV17 on Gaschrom Q (100120 mesh) was employed with a carrier gas of argon/ methane (90:10) at a flow rate of $55 \mathrm{ml} /$ minute. Temperature programming was carried out by maintaining the oven at $195^{\circ} \mathrm{C}$ for 10 minutes followed by increasing $4 \%$ minute up to $260^{\circ}$ and then heating at $260^{\circ}$ for a further 4 minutes. The retention times for timolol and its internal standard were $7 \cdot 1$ and 8.6 minutes respectively. 
Fig. 1 Results of instillation of timolol drops.

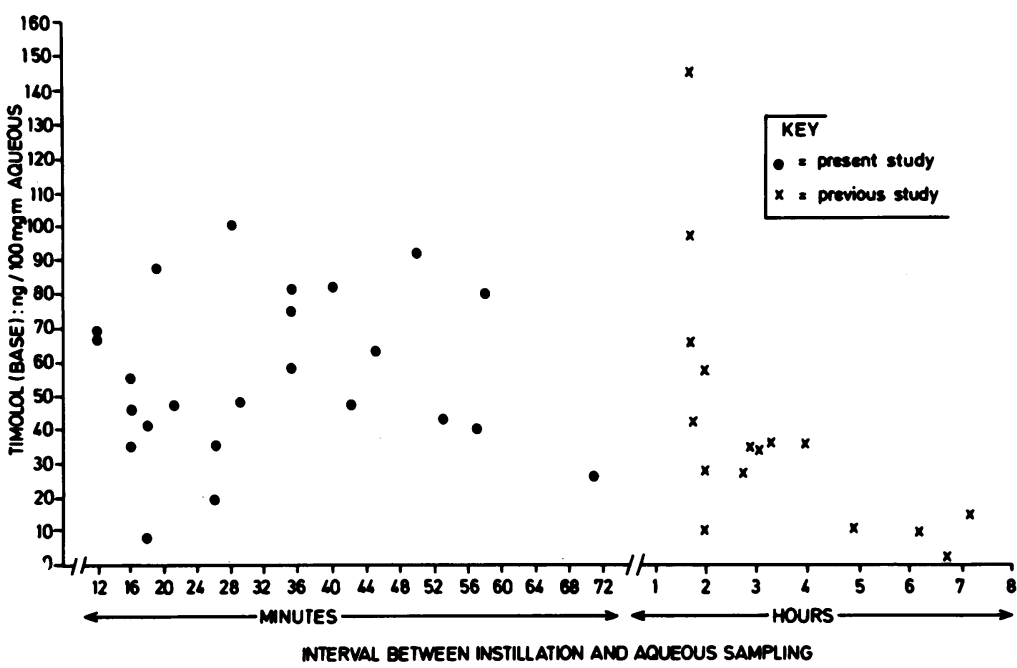

\section{Results}

See Fig. 1, which includes results from our previous study. Within 71 minutes from instillation of drops the concentration of timolol ranged from 8 to $100 \mathrm{ng}$ per $100 \mathrm{mg}$ of aqueous, mean $55 \cdot 46 \mathrm{ng}$.

The results suggest that an individual eye usually achieves a peak concentration within the first 60-70 minutes following instillation of drops, but there seems to be no particularly consistent point of time when that occurs. Actually the highest peak concentration, both series being considered together, was $145 \mathrm{ng}$ at just under 2 hours after instillation.

\section{Discussion}

Previuus studies in rabbits with ${ }^{14} \mathrm{C}$-labelled blockers showed that, after instillation of a $0.5 \%$ solution of timolol, the peak total radioactivity was equivalent to $300-600 \mathrm{ng}$ per $100 \mathrm{mg}$ and occurred at an interval of $30-60$ minutes. $^{2-4}$ That concentration is around 6-10 times higher than the human values we have found, perhaps mainly owing to the thicker human corneoscleral envelope and in spite of the lower turnover of aqueous humour in elderly cataract patients compared with that in rabbits.

The variance of our observations is not particularly large, but artefacts may account for some of it, such as some dilution of aqueous by serum during the process of aspiration. Similarly, the preliminary manipulations of the eye and the anaesthetic used may affect the observations. The analytic chemical technique can be expected to contribute a little to the variance. Residual 'intrinsic' variance can be attributed to differences between patients in tear flow, corneal permeability, tissue uptake, clearance by blood flow in conjunctival and intraocular blood vessels, outflow of aqueous humour, and rate of movement of drug into the lens and vitreous. More general factors are the general state, and especially the age, of the patient as indicators of the rate of metabolism.

This method of using patients having intraocular operations for an unrelated condition provides a useful and probably the only acceptable means of collecting data on drug penetration into the aqueous humour in man as opposed to animals. Although we have not observed any deleterious effect from the aspiration procedure it might be that corneal endothelial function might be more compromised than if the aspiration procedure were omitted: no eye was used if insertion of an intraocular lens was planned.

\section{References}

1 Phillips CI, Bartholomew RS, Kazi G, Schmitt CJ, Vogel R. Penetration of timolol eye drops into human aqueous humour. $\mathrm{Br}$ J Ophthalmol 1981; 65: 593-5.

2 Merck Sharp and Dohme Research Laboratories, USA, and MSD Chibret Research Institute, France. Timolol maleate ophthalmic solutions: preclinical evaluation. 9 January 1978.

3 Ros FE, Innemee HC, Van Zwieten PA. Penetration of atenolol in the rabbit eye. Albrecht von Graefes Arch Klin Ophthalmol 1978; 208: 235-40.

4 Ros FE, Innemee HC, Van Zwieten PA. Ocular penetration of $\beta$-adrenergic blocking agents. An experimental study with atenolol, metoprolol, timolol and propranolol. Doc Ophthalmol 1979; 48: 291-301.

5 Schmitt CJ, Lotti VJ, Le Douarec JC. Penetration of timolol into the rabbit eye. Measurements after ocular instillation and intravenous injection. Arch Ophthalmol 1980; 98: 547-51.

6 Schmitt CJ, Lotti VJ, Le Douarec JC. Penetration of five betaadrenergic antagonists into the rabbit eye after ocular instillation. Albrecht von Graefes Arch Klin Ophthalmol 1981; 217: 167-74.

7 Tocco DJ, De Luna FA, Duncan AEW. Electron capture determination of timolol in human plasma and urine. J Pharm Sci 1975; 64: $1879-81$. 